Annals of Pure and Applied Mathematics

Vol. 15, No. 1, 2017, 145-150

ISSN: 2279-087X (P), 2279-0888(online)

Published on 11 December 2017

www.researchmathsci.org

DOI: http://dx.doi.org/10.22457/apam.v15n1a14

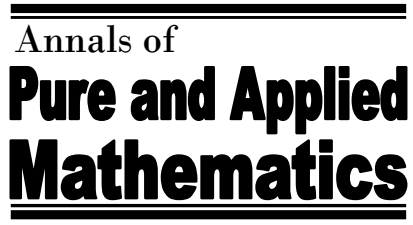

\title{
Fixed Point Theorems in 2-Fuzzy Metric Space
}

Thangaraj Beaula ${ }^{1}$ and P.Jayasingh Manohar ${ }^{2}$

PG and Research Department of Mathematics

TBML College, Porayar, 609307

Email: edwinbeaula@yahoo.co.in

Received 8 November 2017; accepted 9 December 2017

Abstract. The main purpose of this paper is to develop fixed point theorems for self mappings and for the pair of weakly compatible on 2- fuzzy metric space.

Keywords: 2-fuzzy metric space, weakly compatible

AMS Mathematics Subject Classification (2010): 0BE72, 46BXX

\section{Introduction}

The concept of fuzzy sets introduced by Zadeh (1965) became active in the field of research. Kramosil and Michalek [5] in 1975 coined fuzzy metric space which was further modified by George and Veeramani [2] using t-norm. Singh and Chauhan [3] introduced the concepts of compatibility of fuzzy metric and proved fixed point theorems in fuzzy metric space.

In this paper fixed point theorems are established for self mappings and the pair of weakly compatible mappings on 2- fuzzy metric space.

\section{Preliminaries}

Definition 2.1. A binary operation $*:[0,1] \times[0,1] \rightarrow[0,1]$ is called a t-norm if for all $a, b, c, d \in[0,1]$ the following conditions are satisfied

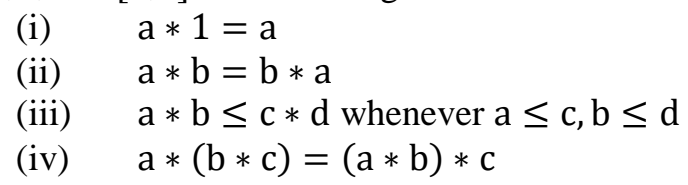

Definition 2.2. The 3 tuple $(X, M, *)$ is called a fuzzy metric space if $X$ is an arbitrary set, $*$ is a continuous t-norm and $\mathrm{M}$ is a fuzzy set in $\mathrm{X}^{2} \times[0, \infty]$ satisfying the conditions.

(M1) $M(x, y, t)=0$

(M2) $M(x, y, t)=1, \quad \forall t>0$ if and only if $x=y$

(M3) $M(x, y, t)=M(y, x, t)$

(M4) $M(x, y, t) * M(y, z, s) \leq M(x, z, t+s)$

(M5) $M(x, y, \cdot):[0, \infty] \rightarrow[0,1]$ is left continuous.

(M6) $\lim _{t \rightarrow \infty} M(x, y, t)=1$ 
Thangaraj Beaula and P.Jayasingh Manohar

Definition 2.3. The 3 tuple $(X, M, *)$ is called a 2- fuzzy metric space if $X$ is an arbitrary set, $*$ is a continuous t-norm and $\mathrm{M}$ is a fuzzy set in $\mathrm{X}^{2} \times[0, \infty]$ satisfying the conditions.

$$
\begin{aligned}
& (2-M 1) M(f, g, t)=0 \\
& (2-M 2) M(f, g, t)=1, \quad \forall t>0 \text { if and only if } f=g \\
& (2-M 3) M(f, g, t)=M(g, f, t) \\
& (2-M 4) M(f, g, t) * M(g, h, s) \leq M(f, h, t+s) \\
& (2-M 5) M(f, g, \cdot):[0, \infty] \rightarrow[0,1] \text { is left continuous. } \\
& (2-M 6) \lim _{t \rightarrow \infty} M(f, g, t)=1
\end{aligned}
$$

\section{Fixed point theorems in 2-fuzzy metric space}

Lemma 3.1. Let $M$ be a 2 -fuzzy metric on $\mathcal{F}(X)$ then $M(f, g, \cdot)$ is nondecreasing for all f, $g \in \mathcal{F}(\mathrm{X})$

Proof: Let $\mathrm{s}, \mathrm{t}>0$ and for all $\mathrm{f}, \mathrm{g} \in \mathcal{F}(\mathrm{X})$.

$$
\text { By (2-M4), M(f,g,t+s) ) } \geq M(f, h, t) * M(h, g, s)
$$

we have $M(f, g, t+s) \geq M(f, h, t) * M(h, g, s)$

If we set $h=g$ then $M(f, h, t+s) \geq M(f, h, t) * M(h, h, s)$

(i.e) $M(f, h, t+s) \geq M(f, h, t)$

Theorem 3.1. Let $(X, M, *)$ be a 2 -fuzzy metric space. If there exists $q \in(0,1)$ such that $M(f, g, q t) \geq M(f, g, t)$ for all $f, g \in \mathcal{F}(X)$ and $t>0$ then $f=g$.

Proof: Since $M(f, g, t) \geq M(f, g, q t)$

$\geq \mathrm{M}(\mathrm{f}, \mathrm{g}, \mathrm{t})$ for all $\mathrm{t}>0$,

impliesM(f, $\mathrm{g}, \mathrm{t})$ is constant

Since $\lim _{t \rightarrow \infty} M(f, g, t)=1$ we get $M(f, g, t)=1$ for all $t>1$

And hence $\mathrm{f}=\mathrm{g}$.

Definition 3.1. Let $(X, M, *)$ be a 2-fuzzy metric space

(i) A sequence $\left\{f_{n}\right\}$ is said to be convergent to $f \in \mathcal{F}(X)$ if for any $r \in(0,1)$ and $\mathrm{t}>0$ there exists $\mathrm{n}_{0} \in \mathrm{N}$ such that for all $\mathrm{n} \geq \mathrm{n}_{0}, \mathrm{M}\left(\mathrm{f}_{\mathrm{n}}, \mathrm{f}, \mathrm{t}\right)>1-r$. That is $\lim _{t \rightarrow \infty} M\left(f_{n}, f, t\right)=1$ for all $t>0$.

(ii) A sequence $\left\{\mathrm{f}_{\mathrm{n}}\right\}$ is said to be a Cauchy sequence if for any $\mathrm{r} \in(0,1)$ and $\mathrm{t}>0$ there exists $\mathrm{n}_{0} \in \mathrm{N}$ such that for all $\mathrm{m}, \mathrm{n} \geq \mathrm{n}_{0}, \mathrm{M}\left(\mathrm{f}_{\mathrm{n}}, \mathrm{f}_{\mathrm{m}}, \mathrm{t}\right)>1-r$.

(iii) A 2-fuzzy metric space in which every Cauchy sequence is convergent is said to be complete.

Definition 3.2. A function $M$ is continuous in the 2-fuzzy metric space if and only if whenever $f_{n} \rightarrow f, g_{n} \rightarrow$ gthen $\lim _{n \rightarrow \infty} M\left(f_{n}, g_{n}, t\right)=M(f, g, t)$.

Definition 3.3. Two mappings A and B on 2-fuzzy metric space are weekly commuting if and only if

$\mathrm{M}(\mathrm{ABf}, \mathrm{BAf}, \mathrm{t}) \geq \mathrm{M}(\mathrm{Af}, \mathrm{Bf}, \mathrm{t})$ for all $\mathrm{f} \in \mathcal{F}(\mathrm{X})$ and $\mathrm{t}>0$. 
Fixed Point Theorems in 2- Fuzzy Metric space

Definition 3.4. Self mappings $A$ and $B$ of a 2 -fuzzy metric space $(X, M, *)$ is said to be compatible if $\lim _{t \rightarrow \infty} M\left(\operatorname{ABf}_{n}, B_{A}, t\right)=1$ for all $t>0$ whenever $\left\{f_{n}\right\}$ is a sequence in $\mathcal{F}(X)$ such that

$$
\lim _{\mathrm{n} \rightarrow \infty} \mathrm{Af}_{\mathrm{n}}=\lim _{\mathrm{n} \rightarrow \infty} \mathrm{Bf}_{\mathrm{n}}=\text { gfor some } \mathrm{g} \in \mathcal{F}(\mathrm{X}) .
$$

Definition 3.5. Suppose $A$ and $B$ be self mappings of 2-fuzzy metric $(X, M, *)$. A point $f$ in $\mathcal{F}(\mathrm{X})$ is called the coincidence point of $\mathrm{A}$ and $\mathrm{B}$ if and only ifAf $=\mathrm{Bf}$. Then $\mathrm{g}=\mathrm{Af}=\mathrm{Bf}$ is called the point of coincidence of Aand B.

Definition 3.6. Self maps A and B are said to be weakly compatible if they commute at their coincidence points that is if $\mathrm{Af}=\mathrm{Bf}$ for some $\mathrm{f} \in \mathcal{F}(\mathrm{X})$ then $\mathrm{ABf}=\mathrm{BAf}$.

Theorem 3.2. Let $(X, M, *)$ be a 2-fuzzy metric space. Let $A, B$ be weakly commuting mappings of $\mathcal{F}(\mathrm{X})$. Let $\left\{\mathrm{f}_{\mathrm{n}}\right\}$ in $\mathcal{F}(\mathrm{X})$. converge to $\mathrm{f}$, such that $\mathrm{Af}_{\mathrm{n}} \rightarrow \mathrm{f}_{\text {and }} \mathrm{Bf}_{\mathrm{n}} \rightarrow \mathrm{f}$ then $\mathrm{A}$ and $\mathrm{B}$ has a coincidence point which is unique.

Proof: Given $\left\{\mathrm{f}_{\mathrm{n}}\right\}$ in $\mathcal{F}(\mathrm{X})$. such that $\mathrm{f}_{\mathrm{n}} \rightarrow \mathrm{f}_{\text {and }} \mathrm{Af}_{\mathrm{n}} \rightarrow \mathrm{f}_{\text {and }} \mathrm{Bf}_{\mathrm{n}} \rightarrow \mathrm{f}$

Since $[A, B]$ is weakly commuting.

$$
M\left(A B f_{n}, B A f_{n}, t\right) \geq M\left(A f_{n}, B f_{n}, t\right) \text { for all } t>0
$$

Then $M(A f, B f, t) \geq M(f, f, t)$ for all $t>0$

Implies $\mathrm{Bf}=\mathrm{Af}=\mathrm{g}$ thus we have a coincidence point for $\mathrm{A}$ and $\mathrm{B}$.

For uniqueness let $h$ be another common fixed point of $A, B$.

Then for all $\mathrm{t}>0, \mathrm{M}(\mathrm{f}, \mathrm{h}, \mathrm{t})=\mathrm{M}(\mathrm{Af}, \mathrm{Bh}, \mathrm{t}) \geq \mathrm{M}(\mathrm{f}, \mathrm{h}, \mathrm{t})$ by (1)

which implies that $f=g$. This completes the proof of the theorem.

Theorem 3.3. Let $A, B, P, Q$ be self maps of a 2-fuzzy metric space $(X, M, *)$. If the pairs $(\mathrm{AB}, \mathrm{P})$ and $(\mathrm{PQ}, \mathrm{B})$ are compatible maps having the same point of coincidence and $\mathrm{AB}=\mathrm{BA}, \mathrm{BP}=\mathrm{PB}, \mathrm{AP}=\mathrm{PA}, \mathrm{PQ}=\mathrm{QP}, \mathrm{PB}=\mathrm{BP}, \mathrm{QB}=\mathrm{BQ}$ then for all $\mathrm{f}, \mathrm{g} \in \mathcal{F}(\mathrm{X}), \mathrm{q} \in$ $(0,1), t>0$

$M(P f, B f, q t) \geq M(P f, P Q g, t) * M(P f, A B f, t) * M(P Q g, B g, t) * M(A B f, P Q g, t) *$ $\mathrm{M}(\mathrm{ABf}, \mathrm{Bg}, \mathrm{t})$.

Then $A, B, P, Q$ have a unique common fixed point in $F(X)$.

Proof: Given the pairs $(A B, P)$ and $(P Q, B)$ are compatible. $(A B, P)$ is compatible iff $\lim _{t \rightarrow \infty} M\left(A B P f_{n}, \operatorname{PABf}_{n}, t\right)=1$ whenever $\left\{f_{n}\right\}$ is a sequence in $F(X)$ such that $\lim A B f_{n}=u$ and $\lim P_{n}=u$

Therefore $\lim _{n \rightarrow \infty} M(A B u, P u, t)=1$

$(P Q, B)$ is compatible if and only if $\lim _{n \rightarrow \infty} M\left(P Q B g_{n}, B P Q g_{n}, t\right)=1$ whenever $\left\{g_{n}\right\}$ is a sequence in $F(X)$ such that $\lim B g_{n}=\lim P Q g_{n}=v$. Therefore

$\lim _{n \rightarrow \infty} M(P Q v, B v, t)=1$

Hence $\mathrm{ABu}=\mathrm{Pu}$ and $\mathrm{PQv}=\mathrm{Bv}$

Thus ' $u$ ' is the coincidence point of $A B \& P$ and ' $v$ ' is the coincidence point of $P Q \& B$. If asserts to prove that $\mathrm{u}=\mathrm{v}$.

Take $\mathrm{f}=\mathrm{f}_{\mathrm{n}}$ and $\mathrm{g}=\mathrm{g}_{\mathrm{n}}$ in $(1)$

$$
\begin{gathered}
M\left(P f_{n}, B g_{n}, q t\right) \geq M\left(P f_{n}, P Q g_{n}, t\right) * M\left(P f_{n}, A B f_{n}, t\right) * M\left(P Q g_{n}, B g_{n}, t\right) \\
* M\left(A B f_{n}, P Q g_{n}, t\right) * M\left(A B f_{n}, B g_{n}, t\right) \\
M(u, v, k t) \geq M(u, v, t) * M(u, u, t) * M(v, v, t) * M(u, v, t) * M(u, v, t) \\
\geq M(u, v, t)
\end{gathered}
$$


Thangaraj Beaula and P.Jayasingh Manohar

Thus by theorem (2) $\mathrm{u}=\mathrm{v}$ which implies that $\mathrm{AB}, \mathrm{P}, \mathrm{PQ}, \mathrm{B}$ have the same coincidence point.

Finally it is to prove that $\mathrm{Au}=\mathrm{Bu}=\mathrm{Pu}=\mathrm{Qu}$.

Take $\mathrm{f}=\mathrm{u}, \mathrm{g}=\mathrm{g}_{\mathrm{n}}$.

$M\left(P u, B g_{n}, q t\right) \geq M\left(P u, P Q g_{n}, t\right) * M(P u, A B u, t) * M\left(P Q g_{n}, B g_{n}, t\right) * M\left(A B u, P Q g_{n}, t\right)$ $* \mathrm{M}\left(\mathrm{ABu}, \mathrm{Bg}_{\mathrm{n}}, \mathrm{t}\right)$

Taking a limit as $\mathrm{n} \rightarrow \infty$ we get

$$
M(P u, v, q t) \geq M(P u, v, t) * M(P u, u, t) * M(v, v, t) * M(u, v, t) * M(u, v, t)
$$

As $u=v$ it implies $M(P u, u, q t) \geq M(P u, u, t)$

Therefore $P u=u$. Take $f=f_{n}$ and $g=u$

$M\left(P f_{n}, B u, q t\right) \geq M\left(P f_{n}, P Q u, t\right) * M\left(P f_{n}, A B f_{n}, t\right) * M(P Q u, B u, t)$

$$
* M\left(A B f_{n}, P Q u, t\right) * M\left(A B f_{n}, B u, t\right)
$$

Taking a limit as $\mathrm{n} \rightarrow \infty$

$\mathrm{M}(\mathrm{u}, \mathrm{Bu}, \mathrm{qt}) \geq \mathrm{M}(\mathrm{u}, \mathrm{PQu}, \mathrm{t}) * \mathrm{M}(\mathrm{u}, \mathrm{u}, \mathrm{t}) * \mathrm{M}(\mathrm{PQu}, \mathrm{Bu}, \mathrm{t}) * \mathrm{M}(\mathrm{u}, \mathrm{u}, \mathrm{t}) * \mathrm{M}(\mathrm{u}, \mathrm{Bu}, \mathrm{t})$ $\geq M(u, B u, t) * M(u, u, t) * M(B u, B u, t) * M(u, u, t) * M(u, B u, t)$

Therefore $M(u, B u, q t) \geq M(u, B u, t)$ which gives $B u=u$. Take $f=B u$ and $g=g_{n}$ $\mathrm{M}\left(\mathrm{PBu}, \mathrm{Bg}_{\mathrm{n}}, \mathrm{qt}\right) \geq \mathrm{M}(\mathrm{PBu}, \mathrm{PQg}, \mathrm{t}) * \mathrm{M}(\mathrm{PBu}, \mathrm{ABBu}, \mathrm{t}) * \mathrm{M}\left(\mathrm{ABBu}, \mathrm{PQg}_{\mathrm{n}}, \mathrm{t}\right)$

$$
* M\left(A B B u, B g_{n}, t\right)
$$

As $\mathrm{A}, \mathrm{B}$ and $\mathrm{P}$ commutes, $\mathrm{ABBu}=\mathrm{BABu}=\mathrm{BPu}=\mathrm{Bu}$ and $\mathrm{PBu}=\mathrm{BPu}=\mathrm{Bu}$

$$
\mathrm{M}(\mathrm{Bu}, \mathrm{u}, \mathrm{qt}) \geq \mathrm{M}(\mathrm{Bu}, \mathrm{u}, \mathrm{t}) * \mathrm{M}(\mathrm{Bu}, \mathrm{Bu}, \mathrm{t}) * \mathrm{M}(\mathrm{Bu}, \mathrm{u}, \mathrm{t})
$$

$$
* \mathrm{M}(\mathrm{Bu}, \mathrm{u}, \mathrm{t})
$$

Therefore $\mathrm{Bu}=\mathrm{u}$

$$
\mathrm{M}(\mathrm{Bu}, \mathrm{u}, \mathrm{qt}) \geq \mathrm{M}(\mathrm{Bu}, \mathrm{u}, \mathrm{t})
$$

Put $\mathrm{f}=\mathrm{Au}$ and $\mathrm{g}=\mathrm{g}_{\mathrm{n}}$

$$
\begin{aligned}
& \mathrm{M}\left(\mathrm{Pau}, \mathrm{Bg}_{\mathrm{n}}, \mathrm{qt}\right) \geq \mathrm{M}\left(\mathrm{PAu}, \mathrm{PQg} g_{n}, \mathrm{t}\right) * \mathrm{M}(\mathrm{PAu}, \mathrm{ABAu}, \mathrm{t}) \\
& \quad * \mathrm{M}\left(\mathrm{PQg}_{\mathrm{n}}, \mathrm{Bg}_{\mathrm{n}}, \mathrm{t}\right) * \mathrm{M}\left(\mathrm{ABAu}, \mathrm{Bg}_{\mathrm{n}}, \mathrm{t}\right) * \mathrm{M}\left(\mathrm{ABAu}, \mathrm{PQg} \mathrm{g}_{\mathrm{n}}, \mathrm{t}\right)
\end{aligned}
$$

As $\mathrm{A}, \mathrm{B}, \mathrm{P}$ commutes $\mathrm{ABAu}=\mathrm{APu}=\mathrm{Au}$ and $\mathrm{PAu}=\mathrm{APu}=\mathrm{Au}$

$$
\mathrm{M}(\mathrm{Au}, \mathrm{u}, \mathrm{qt}) \geq \mathrm{M}(\mathrm{Au}, \mathrm{u}, \mathrm{t}) * \mathrm{M}(\mathrm{Au}, \mathrm{Au}, \mathrm{t}) * \mathrm{M}(\mathrm{u}, \mathrm{u}, \mathrm{t}) * \mathrm{M}(\mathrm{Au}, \mathrm{u}, \mathrm{t}) * \mathrm{M}(\mathrm{Au}, \mathrm{u}, \mathrm{t})
$$

Hence $M(A u, u, q t) \geq M(A u, u, t)$

Therefore $\mathrm{Au}=\mathrm{u}$ Hence $\mathrm{Au}=\mathrm{Bu}=\mathrm{Pu}=\mathrm{u}$ On taking $\mathrm{f}=\mathrm{f}_{\mathrm{n}}$ and $\mathrm{g}=\mathrm{Qf}$, We get $\mathrm{Qu}=\mathrm{uThus} \mathrm{Au}=\mathrm{Bu}=\mathrm{Pu}=\mathrm{Qu}=\mathrm{u}$.

Theorem 3.4. Let $(X, M, *)$ be a complete 2 -fuzzy metric space and let $A, B, S, T$ be mappings from $\mathcal{F}(\mathrm{X})$ into itself such that the following conditions holds.

(i) $\quad \mathrm{AY} \subset \mathrm{TY}, \mathrm{BY} \subset \mathrm{SY}$. where $\mathrm{Y}=\mathcal{F}(\mathrm{X})$

(ii) $\quad \mathrm{A}$ or $\mathrm{B}$ or $\mathrm{S}$ or $\mathrm{T}$ is continuous

(iii) The pair $[\mathrm{A}, \mathrm{S}]$ and $[\mathrm{B}, \mathrm{T}]$ are weakly compatible. Then $\mathrm{A}, \mathrm{B}, \mathrm{S}, \mathrm{T}$ have a unique common fixed point in $\mathrm{X}$

(iv) $\quad M(A f, B g$. qt $) \geq \min \{M(s f, T g, t), M(A f, T g, t), M(S f, B g, 2 t)\}$

Proof: Let $\mathrm{f}_{0}$ be an arbitrary point in $\mathcal{F}(\mathrm{X})$ as $\mathrm{AY} \subset \mathrm{TY}$ and $\mathrm{BY} \subset \mathrm{SY}$. there exists $\mathrm{f}_{1}, \mathrm{f}_{2} \in \mathrm{Y}$ such that $\mathrm{Af}_{0}=\mathrm{Tf}_{1}, \mathrm{Bf}_{1}=\mathrm{Sf}_{2}$

Construct a sequence $\left\{g_{n}\right\}$ in $Y$ such that $g_{2 n+1}=\mathrm{Tf}_{2 n+1}=\mathrm{Af}_{2 \mathrm{n}}$ and $\mathrm{g}_{2 \mathrm{n}}=\mathrm{Sf}_{2 \mathrm{n}}=\mathrm{Bf}_{2 \mathrm{n}-1}$ forn $=1,2, \ldots$ To prove $\left\{\mathrm{g}_{\mathrm{n}}\right\}$ is a Cauchy sequence it is enough to show that

$$
M\left(g_{2 n+1}, g_{2 n+2}, k t\right) \geq M\left(g_{2 n}, g_{2 n+1}, t\right), \forall t>0
$$


Fixed Point Theorems in 2- Fuzzy Metric space

Assume as a contrary

$$
M\left(g_{2 n+1}, g_{2 n+2}, k t\right)<M\left(g_{2 n}, g_{2 n+1}, t\right), \forall t>0
$$

Consider

$$
\begin{gathered}
M\left(g_{2 n+1}, g_{2 n+2}, k t\right)=M\left(A_{2 n}, B f_{2 n+1}, k t\right) \\
\geq \min \left\{M\left(S_{2 n}, T_{2 n+1}, t\right), M\left(A f_{2 n}, T f_{2 n+1}, t\right), M\left(S_{2 n}, B f_{2 n+1}, 2 t\right)\right\} \\
=\min \left\{M\left(g_{2 n}, g_{2 n+1}, t\right), M\left(g_{2 n+1}, g_{2 n+1}, t\right), M\left(g_{2 n}, g_{2 n+2}, 2 t\right)\right\} \\
=\min \left\{M\left(g_{2 n}, g_{2 n+1}, t\right), M\left(g_{2 n}, g_{2 n+2}, 2 t\right)\right\} \\
\geq M\left(g_{2 n+1}, g_{2 n+2}, k t\right)
\end{gathered}
$$

which is a contradiction.

Hence $\left\{\mathrm{g}_{\mathrm{n}}\right\}$ is a Cauchy sequence by completeness of $\mathcal{F}(\mathrm{X})$. It converges to some uin $\mathcal{F}(\mathrm{X})$.

So the subsequence $\left\{\mathrm{Af}_{2 \mathrm{n}}\right\},\left\{\mathrm{Bf}_{2 \mathrm{n}-1}\right\},\left\{\mathrm{Sf}_{2 \mathrm{n}}\right\},\left\{\mathrm{Tf}_{2 \mathrm{n}+1}\right\}$ of $\left\{\mathrm{g}_{\mathrm{n}}\right\}$ also converges to uin $\mathcal{F}(\mathrm{X})$. Since $\mathrm{Af}_{2 \mathrm{n}} \rightarrow \mathrm{u}$ and $\mathrm{Sf}_{2 \mathrm{n}} \rightarrow \mathrm{u}$, and $\mathrm{ASf}_{2 \mathrm{n}} \rightarrow \mathrm{Su}, \mathrm{S}$ is continuous $\mathrm{SAf}_{2 \mathrm{n}} \rightarrow \mathrm{Su}$ and $\mathrm{SSf}_{2 \mathrm{n}} \rightarrow$ Su.

Put $\mathrm{f}=\mathrm{Sf}_{2 \mathrm{n}}$ and $\mathrm{g}=\mathrm{f}_{2 \mathrm{n}-1}$ in (1) then

$$
M\left(A S f_{2 n}, B f_{2 n-1}, q t\right) \geq \min \left\{M\left(S S f_{2 n}, T f_{2 n-1}, t\right), M\left(A S f_{2 n-1}, T_{2 n-1}, t\right), M\left(S S f_{2 n}, B f_{2 n}, t\right)\right\}
$$

As $n \rightarrow \infty M(S u, u, q t) \geq \min \{M(S u, u, t), M(S u, u, t), M(S u, u, t)\}$

which implies $\mathrm{Su}=\mathrm{u}$

$$
=\mathrm{M}(\mathrm{Su}, \mathrm{u}, \mathrm{t})
$$

Again put $\mathrm{f}=\mathrm{u}$ and $\mathrm{g}=\mathrm{f}_{2 \mathrm{n}-1}$ then (1) implies

$$
M\left(A u, B f_{2 n-1}, q t\right) \geq \min \left\{M\left(S u, T_{2 n-1}, t\right), M\left(A u, T f_{2 n-1}, t\right), M\left(S u, B f_{2 n-1}, t\right)\right\}
$$

Allow $n \rightarrow \infty$ then $M(A u, u, q t) \geq M(A u, u, t)$

Therefore $\mathrm{Au}=\mathrm{u}$.

Since $\mathrm{A}(\mathcal{F}(\mathrm{X})) \subset \mathrm{T}(\mathcal{F}(\mathrm{X}))$ there exists $\mathrm{h} \in \mathcal{F}(\mathrm{X})$

such that $\mathrm{u}=\mathrm{Au}=\mathrm{Th}$ Put $\mathrm{f}=\mathrm{u}$ and $\mathrm{g}=\mathrm{h}$ in (1) then

$M(A u, B h, q t) \geq \min \{M(S u, T h, t), M(A u, T h, t), M(S u, B h, t)\}$

thenM(f, Bh, qt $) \geq M(u, B h, t)$ which implies $u=B h$

Since $\mathrm{B}$ and $\mathrm{T}$ are weakly compatible they commute at their coincidence points that if $\mathrm{Bh}=\mathrm{Th}$ for some $\mathrm{P} \in \mathcal{F}(\mathrm{X})$ then $\mathrm{BTh}=\mathrm{TBh}$.

Therefore $\mathrm{Bg}=\mathrm{BTh}=\mathrm{TBh}=\mathrm{Tu}$. Finally put $\mathrm{f}=\mathrm{u}$ and $\mathrm{g}=\mathrm{u}$ in (1)

Then $M(A u, B u, q t) \geq \min \{M(S u, T u, t), M(A u, T u, t), M(S u, B u, t)\}$

Allow $\mathrm{n} \rightarrow \infty$ then $\mathrm{M}(\mathrm{u}, \mathrm{Bu}, \mathrm{qt}) \geq \mathrm{M}(\mathrm{u}, \mathrm{Bu}, \mathrm{t})$

Therefore $\mathrm{Bu}=\mathrm{u}$ hence $\mathrm{Au}=\mathrm{Bu}=\mathrm{Su}=\mathrm{Tu}=\mathrm{u}$.

Thus ' $u$ ' is a common fixed point of $A, B, S, T$ similarly we can prove when $A$ is continuous and $(\mathrm{A}, \mathrm{S})$ is weakly compatible.

Similarly we can prove when B is continuous.

Now to prove the uniqueness of the fixed point assume that ' $l$ ' is another common fixed point of $\mathrm{A}, \mathrm{B}, \mathrm{S}, \mathrm{T}$

Then $l=\mathrm{A} l=\mathrm{B} l=\mathrm{S} l=\mathrm{T} l$ Put $\mathrm{f}=\mathrm{u}$ and $\mathrm{g}=l$ in (1) then

$$
\mathrm{M}(\mathrm{Au}, \mathrm{B} l, \mathrm{qt}) \geq \min \{\mathrm{M}(\mathrm{Su}, \mathrm{T} l, \mathrm{t}), \mathrm{M}(\mathrm{Au}, \mathrm{T} l, \mathrm{t}), \mathrm{M}(\mathrm{Su}, \mathrm{B} l, \mathrm{t})\}
$$

$\mathrm{M}(\mathrm{u}, l, \mathrm{qt}) \geq \mathrm{M}(\mathrm{u}, l, \mathrm{t})$ which implies $\mathrm{u}=l$.

\section{REFERENCES}


Thangaraj Beaula and P.Jayasingh Manohar

1. A.Jain and R.Singh, A fixed point theorem for compatible mappings of type (A) in fuzzy metric space, Acta Ciencia India. Vol XXXIII M,No. 2(2007) 339-346.

2. A.George and P.Veeramani, On some results in fuzzy metric spaces, Fuzzy Sets and Systems, 64 (1994) 395-399.

3. B.Singh and M.S.Chouhan, Common fixed points of compatible maps in Fuzzy metric spaces, Fuzzy Sets and Ssystems, 115 (2000) 471-475.

4. G.Jangck, P.P.Murthy and Y.J.Cho, Compatible maps of type (A) and common fixed points, Math. Japonica, 38 (1993) 381-390.

5. I.Kramosil and J.Michalek, Fuzzy metric and statistical metric spaces, Kybermotica, 11 (1975) 336-344.

6. K.Wadhwal, F.Beg and H.Dubey, Common fixed points theorem for sub compatible and sub sequentially continuous maps in fuzzy metric spaces using implicit relation, URRAS, 9 (1) (2011) 87.

7. L.A.Zadeh, Fuzzy sets, Information and Control, 89 (1965) 338-353. 